\section{Case Reports in Neurology}

Case Rep Neurol 2020;12:452-459

DOI: 10.1159/000509682

Published online: November 26, 2020 (c) 2020 The Author(s)

Published by S. Karger AG, Basel www.karger.com/crn

This article is licensed under the Creative Commons Attribution-NonCommercial 4.0 International License (CC BY-NC) (http://www.karger.com/Services/OpenAccessLicense). Usage and distribution for commercial purposes requires written permission.

\title{
Bell's Palsy in Pregnancy: A Case Series
}

\author{
Sumonthip Leelawai ${ }^{a} \quad$ Pornchai Sathirapanya $^{\mathrm{a}} \quad$ Chitkasaem Suwanrath $^{\mathrm{b}}$ \\ aDivision of Neurology, Department of Internal Medicine, Faculty of Medicine, Prince of \\ Songkla University, Hat Yai, Thailand; 'bepartment of Obstetrics and Gynecology, Faculty \\ of Medicine, Prince of Songkla University, Hat Yai, Thailand
}

\section{Keywords}

Bell's palsy · Pregnancy · Preeclampsia - Gestational hypertension

\begin{abstract}
The association between pregnancy-associated Bell's palsy (PABP) and gestational hypertension (GHT), preeclampsia (PE), and eclampsia (EC) remains inconclusive. We aimed to study the characteristics of PABP cases and the neonatal outcomes at our institution. All cases diagnosed with PABP from 2006 to 2016 were identified. Demographic and clinical characteristics including maternal age, previous medical and obstetric illnesses, gestational age at the onset of PABP, the development of PE/EC, GHT, gestational diabetes mellitus (GDM), treatment and outcomes, as well as neonatal health indices and anomalies were described. Eight patients with PABP were identified. Most of the cases were first- or second-gravidity pregnancies. PABP occurred during the third trimester except for one case in whom PABP developed 2 days postpartum. No PABP case associated with EC was found. PE was found in only one case in whom GHT occurred in a previous pregnancy. Moreover, GHT combined with GDM was found in a case with previous GHT. The recovery of PABP was satisfactory. Previous obstetric complications are associated with the current PE, GHT and GDM. Facial weakness recovers favorably regardless of treatment and the neonatal outcomes are overall satisfactory.
\end{abstract}




\section{Case Reports in Neurology}

\begin{tabular}{l|l}
\hline Case Rep Neurol 2020;12:452-459 \\
\hline DOI: 10.1159/000509682 & $\begin{array}{l}\text { @ 2020 The Author(s). Published by S. Karger AG, Basel } \\
\text { www.karger.com/crn }\end{array}$ \\
\hline
\end{tabular}

Leelawai et al.: Bell's Palsy in Pregnancy: A Case Series

\section{Introduction}

Bell's palsy (BP) or idiopathic peripheral facial palsy is the most common acute unilateral peripheral facial paralysis encountered in clinical services. The definite etiology and pathogenesis of BP have not been elucidated. Although reactivation of latent herpes simplex virus infection in the geniculate ganglions of facial nerves (FNs) is commonly attributed, thrombosis of the vasa nervorum of FNs resulting in ischemic facial neuropathy has been hypothesized [1]. Furthermore, recent studies revealed that alteration of immune regulation by changing the $\mathrm{T}$ and $\mathrm{B}$ lymphocyte subpopulations (CD3+, CD4+, and CD8+) and macrophages played a role in the development of BP. In addition, the reactions to some specific immune mediators (e.g., IL-6, IL-8, and TNF- $\alpha$ ) released from these cells were also postulated to cause FN inflammation resulting in BP [2-4]. A group of common late pregnancy-associated disorders (LPADs) including gestational hypertension (GHT), gestational diabetes mellitus (GDM), or preeclampsia (PE)/eclampsia (EC) are known to be associated with microcirculation failure of the placenta. These LPADs frequently occur during the late third trimester and immediate postpartum period. Some growing scientific evidence also suggested that an immunologic reaction causing microvascular inflammation was an underlying pathogenic mechanism of the LPADs as well $[3,4]$. The onset of pregnancy-associated Bell's palsy (PABP) is in the same period as that of LPADs, and the proposed pathogenic mechanisms of PABP are comparable to those of LPADs. Based only on clinical observation, some previous studies speculated a close association between PABP and LPADs [1, 5-9]. Several articles also hypothesized that PABP was a risk factor of LPADs, particularly PE $[1,6,8]$.

This case series aimed to make a primary study of the clinical characteristics of PABP cases, the associated LPADs as well as the outcomes of newborns of mothers with PABP. Additionally, the possible pathogeneses relating PABP to LPADs were discussed.

\section{Methods}

This was a retrospective case series reporting the obstetric characteristics of the pregnant women with PABP and the health status of their newborns in Songklanagarind Hospital from January 2006 to December 2016. Our institution is an 846-bed referral medical center in southern Thailand.

Bell's palsy (BP) was defined by an acute unilateral peripheral facial paralysis without explainable cause as mentioned before. We included all pregnant women who developed BP during the period of their pregnancies until 6 weeks postpartum and defined them as PABP cases. The collected data included patient characteristics, previous obstetric and general medical illnesses, current antenatal care history and blood tests, gestational age at the onset of PABP, treatment of PABP, and the recovery status of the facial weakness. GHT and GDM, based on the diagnostic criteria, were carefully explored in all PABP cases. The recovery of facial weakness was classified by the House-Brackmann Score into favorable (1-2), or unfavorable $(\geq 3)$.

We defined GHT and GDM according to the standard practical definitions. GHT was defined by an elevation of blood pressure (systolic blood pressure $\geq 140 \mathrm{~mm} \mathrm{Hg}$ or diastolic blood pressure $\geq 90 \mathrm{~mm} \mathrm{Hg}$ ), which developed after 20 weeks of gestation in a previously 


\section{Case Reports in Neurology}

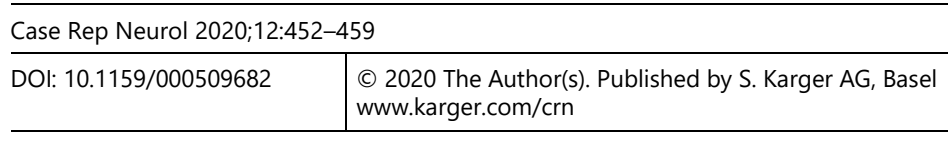

Leelawai et al.: Bell's Palsy in Pregnancy: A Case Series

normotensive woman and absence of proteinuria, and the blood pressures returned to normal by 12 weeks postpartum. PE was defined by a systolic blood pressure $\geq 140 \mathrm{~mm} \mathrm{Hg}$ or a diastolic blood pressure $\geq 90 \mathrm{~mm} \mathrm{Hg}$ plus the presence of at least one of the following: (a) 1+ proteinuria on urine dipstick, (b) proteinuria $>300 \mathrm{mg} / 24 \mathrm{~h}$, (c) urine protein-to-creatinine ratio of 0.3 or more [10]. GDM was diagnosed following the standard diagnostic criteria as follows: once the blood glucose screening test by 50-g oral glucose challenge test (50 g GCT) at $1 \mathrm{~h}$ was $\geq 140 \mathrm{mg} / \mathrm{dL}$, a 3-h 100-g oral glucose tolerance test (100 g OGTT) was further done. The diagnosis of GDM was made when two or more of the plasma glucose levels were met. The defined plasma glucose levels of 100-g OGTT were as follows: (a) fasting plasma glucose $>95$ $\mathrm{mg} / \mathrm{dL}$, (b) 1st-hour plasma glucose $>180 \mathrm{mg} / \mathrm{dL}$, (c) 2 nd-hour plasma glucose $>155 \mathrm{mg} / \mathrm{dL}$, and (d) 3rd-hour plasma glucose $>140 \mathrm{mg} / \mathrm{dL}$ [11].

The neonatal characteristics of the newborns of PABP mothers included maternal gestational age at the birth of newborns, the presence of birth anomalies, birth weight, body length, placental weight, cord length, and the APGAR scores at 1 and 5 min after birth [12].

The recovery of the facial paralysis in PABP women and the outcomes of the neonates were summarized. A relevant literature review was done.

\section{Results}

There were 8,756 deliveries during the study period. Out of these, 8 patients diagnosed with PABP were identified. The mean \pm SD maternal age at the onset of PABP was $30.0 \pm 5.5$ years. $\mathrm{PABP}$ occurred during the first and second gestation in $6 / 8$ cases. The mean gestational age at the onset of PABP was 33.65 weeks.

One case (Case 6) had both GDM and GHT. Moreover, case 7 developed PE during the current pregnancy with PABP. Both cases were high order of gravidity (G4 and G5, respectively), and had previous histories of GHT. No case of EC associated with PABP was found. Favorable recovery from the facial paralysis was obtained in most of the PABP women in this series, regardless of treatment (Table 1 ).

The overall mean \pm SD neonatal birth weight was 2,680 $\pm 856.8 \mathrm{~g}$. One newborn (Case 7), whose mother had PE, was a preterm baby with low APGAR scores and respiratory compromise for which assisted respiration was required. Congenital anomaly was noted in one neonate at the 6th week of gestational age. This neonate was born from a woman with GDM and GHT (Case 6). The mean \pm SD of the placental weight was $583 \pm 256.2 \mathrm{~g}$. The mean \pm SD of the cord length was $50.8 \pm 5.6 \mathrm{~cm}$. However, we did not find any poor neonatal outcomes among the newborns of otherwise normal PABP mothers (Table 2).

\section{Discussion}

We found 8 PABP cases in our retrospective review. Seven patients acquired PABP during the third trimester, while only one case had facial paralysis on the second day postpartum. Most of the PABP cases (6/8 cases) were the mothers of first or second gravidity. Only two of 


\section{Case Reports in Neurology}

Case Rep Neurol 2020;12:452-459

DOI: $10.1159 / 000509682$

(C) 2020 The Author(s). Published by S. Karger AG, Basel www.karger.com/crn

Leelawai et al.: Bell's Palsy in Pregnancy: A Case Series

them were multiparous (G4P3 and G5P4) mothers who had associated GHT combined with GDM, and PE, respectively (Cases 6 and 7). It is noteworthy that one PABP case with GHT and GDM (Case 6) and another one with PE (Case 7) had GHT in their previous pregnancies. In contrast to the attribution of PABP to PE development in the literature, we found no obvious number of cases with PE in PABP mothers in our series.

Since most of the previous reports are based mostly on clinical observations of a few cases or a small case series due to the rarity of PABP cases. Similarly, the very small number of PABP cases significantly limits the strength of conclusion regarding the association between PABP and PE/EC in our study as well. A large case series including 41 PABP cases performed in Canada concluded that PABP was probably associated with GHT, PE, and other pregnancy-related adverse events. The study expected that GHT and PE together had a five-fold higher incidence in mothers with PABP than the national expected average rate [1]. Another study of 42 PABP cases which were compared with 242,174 unmatched controls (without PABP) revealed a significantly higher rate of severe PE and cesarean section deliveries, but no significantly undesired perinatal outcomes existed [8]. Due to the paucity of such cases in obstetric practice and research, PABP as a significant risk factor for the development of GHT and PE/EC cannot be concluded. To date, no well-designed case-control study matching maternal age, prenatal cardiovascular disorders, gravidity, and parity between pregnancies with and without PABP to evaluate the presence of PABP as a risk of GHT or PE/EC has been conducted.

The recovery of PABP was claimed to be unsatisfactory in a few studies $[1,13,14]$. A case report of PABP stressed that the facial paralysis that progressed to complete palsy 10 days after the onset was associated with poorer outcomes [13]. Actually, this prognostic indicator for poorer recovery of facial paralysis is also reported in the general population with BP. The severity and duration of progression of facial paralysis directly reflect the severity of FN inflammation but inversely correlate with the rate of recovery [15]. In general, the treatment of BP with oral prednisolone yields a favorable outcome. We consider that pregnancy per se may not contribute any effect on the recovery of facial paralysis.

The pathogenesis of GHT, PE, essential hypertension (EHT), and pulmonary hypertension have been elucidated. Immunologically induced endothelial inflammation and injury associated with cell-mediated immunity, i.e., CD4+ helper T cells, CD8+ T cells, B cells, dendritic cells, uterine natural killer cells, macrophages, and a variety of related cytokines were described $[16,17]$. The combination of cellular immune responses and cytokines reactions resulted in changes in vessel wall structures and vascular tone, leading to increased vascular permeability, increased vascular resistance, and finally elevated blood pressure through stimulation of the rennin-angiotensin system [18]. Moreover, the imbalance of the activity of CD4+ helper Tcell subpopulations and excessive expression and activation of CD4+ helper T-17 cells with downregulation of regulatory $\mathrm{T}$ cells was specially emphasized as a key pathogenesis of endothelial inflammatory injury in both GHT and EHT $[15,17]$. Therefore, GHT, PE, PABP, and EHT may share the same immunological mechanism described, but the different conditions and specific precipitating factors can trigger the different clinical presentations. We propose that immune-mediated demyelination of the FNs related to late pregnancy alone, or microangiopathy of the vasa nervorum of the FNs, or both is a possible pathogenic mechanism to cause PABP. 


\section{Case Reports in Neurology}

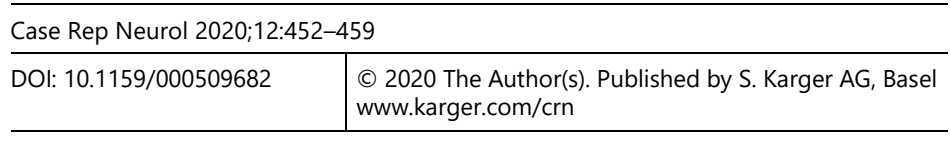

Leelawai et al.: Bell's Palsy in Pregnancy: A Case Series

Although congenital anomalies, a higher rate of cesarean section deliveries, and intrauterine growth retardation were occasionally reported among cases with PABP $[1,7]$, there was generally no significant unfavorable neonatal outcome in a large retrospective study [8]. Similarly, the neonatal outcomes of our study were satisfactory.

The limitations of the current study include a single-center, retrospective nature of the study, and particularly, the rarity of PABP cases. These limitations impede the finalization for reliable conclusions. We expect that a well-designed, multi-center, and matched case-control study matching maternal age, gravidity, parity, and various maternal metabolic characteristics may be more useful in determining the true risk of GDM, GHT, and PE/EC development in PABP women.

\section{Conclusion}

The association between PABP and late gestational complications has remained inconclusive. We suggest that the PABP women who have no previous obstetric disorder are very less likely to have pregnancy-related complications. PABP by itself has no adverse impact on both the recovery of facial paralysis and the neonatal outcomes.

\section{Acknowledgement}

The authors would like to express their appreciation to David Patterson of the Foreign Affairs Unit of the Faculty of Medicine, Prince of Songkla University, for editing the English of the manuscript.

\section{Statement of Ethics}

The case report was reviewed and approved by the Ethics Committee of the Faculty of Medicine, Prince of Songkla University (registration No. 60-132-14-4). All personal and identifiable information of the patients were completely anonymized. All subjects have given their written informed consent to publish their cases. We strictly followed the guideline of the 1964 Declaration of Helsinki and its related good practice guidelines in writing this case report.

\section{Conflicts of Interest Statement}

The authors declare that they have no conflicts of interest to declare.

\section{Karger'=}




\section{Case Reports in Neurology}

\begin{tabular}{l|l}
\hline Case Rep Neurol 2020;12:452-459 \\
\hline DOI: 10.1159/000509682 & $\begin{array}{l}\text { (c) 2020 The Author(s). Published by S. Karger AG, Basel } \\
\text { www.karger.com/crn }\end{array}$ \\
\hline
\end{tabular}

Leelawai et al.: Bell's Palsy in Pregnancy: A Case Series

\section{Funding Sources}

No grant or support was received.

\section{Author Contributions}

Sumonthip Leelawai: conceptualization of the content; writing the preliminary version of the manuscript; reviewing and approving the final manuscript before submission.

Pornchai Sathirapanya: conceptualization of the overall academic content; co-writing of the preliminary version; editing the final version and approving it before submission.

Chitkasaem Suwanrath: conceptualization of the academic content related to obstetrics; editing the final version and approving it before submission.

\section{References}

1 Shmorgun D, Chan WS, Ray JG. Association between Bell's palsy in pregnancy and pre-eclampsia. QJM. 2002 Jun;95(6):359-62.

2 Yilmaz M, Tarakcioglu M, Bayazit N, Bayazit YA, Namiduru M, Kanlikama M. Serum cytokine levels in Bell's palsy. J Neurol Sci. 2002 May;197(1-2):69-72.

3 Greco A, Gallo A, Fusconi M, Marinelli C, Macri GF, de Vincentiis M. Bell's palsy and autoimmunity. Autoimmun Rev. 2012 Dec;12(2):323-8.

4 El Sawy NA, Shahine EM, Alhadidi AS, Achmawi GA, Alhabashy NM. Cellular immune response in prognosis of Bell's palsy and its relation to clinical and electrophysiological findings. Alex J Med. 2012;48(3):233-40.

5 Vrabec JT, Isaacson B, Van Hook JW. Bell's palsy and pregnancy. Otolaryngol Head Neck Surg. 2007 Dec;137(6):858-61.

6 Pourrat O, Neau JP, Pierre F. Bell's palsy in pregnancy: underlying HELLP syndrome or pre-eclampsia? Obstet Med. 2013 Sep;6(3):132-3.

7 Mylonas I, Kästner R, Sattler C, Kainer F, Friese K. Idiopathic facial paralysis (Bell's palsy) in the immediate puerperium in a patient with mild preeclampsia: a case report. Arch Gynecol Obstet. 2005 Sep;272(3):241-3.

8 Katz A, Sergienko R, Dior U, Wiznitzer A, Kaplan DM, Sheiner E. Bell's palsy during pregnancy: is it associated with adverse perinatal outcome? Laryngoscope. 2011 Jul;121(7):1395-8.

9 Ragupathy K, Emovon E. Bell's palsy in pregnancy. Arch Gynecol Obstet. 2013 Jan;287(1):177-8.

10 American College of Obstetricians and Gynecologists; Task Force on Hypertension in Pregnancy. Hypertension in pregnancy. Report of the American College of Obstetricians and Gynecologists' Task Force on Hypertension in Pregnancy. Obstet Gynecol. 2013 Nov;122(5):1122-31.

11 Whalen KL, Taylor JR. Gestational Diabetes Mellitus. PSAP 2017: Book 1 [cited 2020 March 10]. Available from: https://www.accp.com/docs/bookstore/psap/p2017b1_sample.pdf.

12 American Academy of Pediatrics, Committee on Fetus and Newborn: American College of Obstetricians and Gynecologists Committee on Obstetric Practice. The Apgar Score. Pediatrics. 2015 Oct;136(4):819-22.

13 Gillman GS, Schaitkin BM, May M, Klein SR. Bell's palsy in pregnancy: a study of recovery outcomes. Otolaryngol Head Neck Surg. 2002 Jan;126(1):26-30.

14 Phillips KM, Heiser A, Gaudin R, Hadlock TA, Jowett N. Onset of Bell's palsy in late pregnancy and early puerperium is associated with worse long-term outcomes. Laryngoscope. 2017 Dec;127(12):2854-9.

15 Sathirapanya P, Sathirapanya C. Clinical prognostic factors for treatment outcome in Bell's palsy: a prospective study. J Med Assoc Thai. 2008 Aug;91(8):1182-8.

16 Jafri S, Ormiston ML. Immune regulation of systemic hypertension, pulmonary arterial hypertension, and preeclampsia: shared disease mechanisms and translational opportunities. Am J Physiol Regul Integr Comp Physiol. 2017 Dec;313(6):R693-705. 


\section{Case Reports in Neurology}

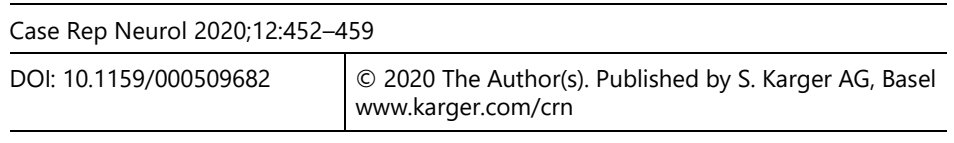

Leelawai et al.: Bell's Palsy in Pregnancy: A Case Series

17 Faas MM, De Vos P. Innate immune cells in the placental bed in healthy pregnancy and preeclampsia. Placenta. 2018 Sep;69:125-33.

18 LaMarca B, Cornelius DC, Harmon AC, Amaral LM, Cunningham MW, Faulkner JL, et al. Identifying immune mechanisms mediating the hypertension during preeclampsia. Am J Physiol Regul Integr Comp Physiol. 2016 Jul;311(1):R1-9.

Table 1. Characteristics of pregnant women with PABP

\begin{tabular}{|c|c|c|c|c|c|c|c|c|}
\hline Case & & $\begin{array}{l}\text { Gravidity, } \\
\text { parity, abortion } \\
\text { (GPA) }\end{array}$ & $\begin{array}{l}\text { GDM } \\
\text { screening } \\
\text { test* }\end{array}$ & $\begin{array}{l}\text { Pregnancy- } \\
\text { related } \\
\text { hypertension }\end{array}$ & $\begin{array}{l}\text { Gestational age at } \\
\text { onset of PABP, we }\end{array}$ & $\begin{array}{l}\text { Treatment of } \\
\text { PABP }\end{array}$ & Outcomes & $\begin{array}{l}\text { Previous obstetric } \\
\text { complications } \\
\text { (gestation) }\end{array}$ \\
\hline 1 & 24 & G2P1 & normal & none & 35 & prednisolone & favorable & \\
\hline 2 & 26 & G1 & normal & none & 40 & prednisolone & favorable & \\
\hline 3 & 27 & G1 & normal & none & 35 & prednisolone & favorable & \\
\hline 4 & 28 & G1 (twin) & normal & none & 37 & none & favorable & \\
\hline 5 & 35 & G2P1 & normal & none & 38 & prednisolone & unfavorable & \\
\hline 6 & 36 & G4P3 & GDM & GHT & 25 & none & unfavorable & GHT (G2) \\
\hline 7 & 37 & G5P4 & normal & preeclampsia & 27 & prednisolone & favorable & GHT (G4) \\
\hline 8 & 37 & G2P1 & normal & none & postpartum day 2 & prednisolone & favorable & \\
\hline
\end{tabular}

* GDM screening test: GDM was diagnosed following the diagnostic criteria of the American College of Obstetricians and Gynecologists (ACOG). If the plasma glucose level from a 1 - $\mathrm{h}, 50$-g oral glucose challenge test (50-g GCT) is $\geq 140 \mathrm{mg} / \mathrm{dL}$, then a 3 - $\mathrm{h}$, 100 -g oral glucose tolerance test (100-g OGTT) is further done. Diagnosis of GDM is made when two or more of the plasma glucose values were met. The defined plasma levels of 100-g OGTT are as follows: (a) fasting plasma glucose $>95 \mathrm{mg} / \mathrm{dL}$, (b) 1st-hour plasma glucose $>180 \mathrm{mg} / \mathrm{dL}$, (c) 2nd-hour plasma glucose $>155$ $\mathrm{mg} / \mathrm{dL}$, or (d) 3rd-hour plasma glucose $>140 \mathrm{mg} / \mathrm{dL}$. Patients with a fasting plasma glucose level $>126 \mathrm{mg} / \mathrm{dL}$, or $2 \mathrm{nd}$-hour plasma glucose $>200$ $\mathrm{mg} / \mathrm{dL}$ following a 75-g oral glucose loading test, or random plasma glucose $>200 \mathrm{mg} / \mathrm{dL}$ in the presence of diabetes symptoms were considered as overt diabetes mellitus in pregnancy.

PABP, pregnancy-associated Bell's palsy; GDM, gestational diabetes mellitus; GHT, gestational hypertension. 
Case Reports in

Neurology

\begin{tabular}{l|l}
\hline Case Rep Neurol 2020;12:452-459 \\
\hline DOI: 10.1159/000509682 & $\begin{array}{l}\text { @ 2020 The Author(s). Published by S. Karger AG, Basel } \\
\text { www.karger.com/crn }\end{array}$ \\
\hline
\end{tabular}

Leelawai et al.: Bell's Palsy in Pregnancy: A Case Series

Table 2. Characteristics of the newborns of the corresponding PABP mothers in Table 1

\begin{tabular}{llllllll}
\hline No. & $\begin{array}{l}\text { Gestational age } \\
\text { at birth, weeks }\end{array}$ & $\begin{array}{l}\text { Placental } \\
\text { weight, }\end{array}$ & $\begin{array}{l}\text { Cord } \\
\text { length, cm }\end{array}$ & $\begin{array}{l}\text { Birth weight, } \\
\text { g }\end{array}$ & $\begin{array}{l}\text { Length, } \\
\text { cm }\end{array}$ & $\begin{array}{l}\text { APGAR } \\
\text { scores* 1, 5 }\end{array}$ & $\begin{array}{l}\text { Birth anomalies and com- } \\
\text { plications }\end{array}$ \\
\hline 1 & 39 & 800 & 60 & 2,650 & 48 & 8,10 & \\
2 & 40 & 600 & 50 & 3,180 & 54 & 9,9 & \\
3 & 39 & 400 & 56 & 3,902 & 55 & 9,10 & \\
4 & 37 & 900 & 48,52 & $2,508,2,330$ & 48,47 & 8,$9 ; 9,9$ & twin \\
5 & 38 & 800 & 60 & 2,750 & 55 & 9,10 & fetal bilateral club feet \\
6 & 36 & 700 & 50 & 2,540 & 52 & 9,10 & and fetal distress \\
& & & & & & & respiratory failure \\
7 & 27 & 200 & 45 & 1,140 & 37.5 & $3,5 \mathrm{~T}$ & \\
8 & 38 & 600 & 45 & 3,050 & 49 & 9,10 & \\
\hline
\end{tabular}

* APGAR scores 1, 5: A, Activity; P, Pulse; G, Grimace; A, Appearance; R, Respiration. A rapid scoring system assessing the clinical status of the newborn infant at 1 and $5 \mathrm{~min}$ of age, each of which is given a score of 0 , 1 , or 2 . The score is reported at 1 and $5 \mathrm{~min}$ after birth for all infants, and at 5 -min intervals thereafter until $20 \mathrm{~min}$ for infants with a score $<7$. However, based on population-based studies, APGAR scores of $<5$ at 5 min and $10 \mathrm{~min}$ are associated with an increased relative risk of cerebral palsy, and the degree of abnormality correlates with the risk of cerebral palsy.

PABP, pregnancy-associated Bell's palsy; T, endotracheal intubation and assisted respiration were required. 